\title{
Gender in urology
}

\author{
Axel S. Merseburger · Franziska Gätcke • \\ Mesut Remzi
}

Received: 29 August 2013/ Accepted: 2 September 2013/Published online: 21 September 2013

(C) Springer-Verlag Berlin Heidelberg 2013

The sex-gender debate has emerged from the USA as a political movement of the late 1960s and 1970s and addressed the question: What makes a woman a woman and what makes a man a man? Biological conditions (sex) or sociocultural aspects (gender)?

However, the concept of gender, especially the importance of a proper understanding of the sex/gender relations, did not find entrance into the medical discourse until the twenty-first century when the medical community discovered that 'women are not small men' and that medicine, therapeutic strategies, medication and most diagnostics were aimed and proofed only at men [1]. The aspirin story elucidates the importance of gender issues. In the US physician study, aspirin showed an outstanding protective effect in cardiovascular system, and the study was discontinued due to ethical factors [2]. Since that time, aspirin was the most sold medicine worldwide; however, it was not tested in a single woman. Today, we know that aspirin only reduced the risk of stroke, but not of myocardial infarction in women [3]. After checking for gender, aspirin is only recommended to high-risk female patient under the age of 65 years [4].

The need to regard differences and similarities in men and women as medical research and clinical practice leads to the formation of a 'personalised medicine' that not only considers all individual risk factors of a human being (e.g. race, ethnicity, lifestyle factors, personal history, genetic

\section{A. S. Merseburger $(\square) \cdot$ F. Gätcke}

Hannover Medical School, Hannover, Germany

e-mail: Merseburger.Axel@mh-hannover.de

\section{Remzi}

Landesklinikum Korneuburg, Urologie,

Wiener Ring 3-5, 2100 Korneuburg, Österreich predisposition) but also acknowledges gender- and sexrelated differences in health behaviour, aetiopathogenesis and treatment [5].

Nonetheless, it is still a challenge to define gender medicine clearly: the theoretical problem lies in the juxtaposition between gender as a sociocultural process and medical and therefore biological hypotheses-despite the initial ambition of gender-related research to separate the two terms and their meaning.

Yet, diseases are more sex- and gender-conditioned than long time expected. They have major consequences on the practice of medicine, on outcomes and on choice and efficacy of therapy [6]. At first, endocrine and reproductive systems were the logical areas to observe the effects of gender on medicine. But for some time now, it has been common sense that women and men also differ in diseases such as diabetes, various cardiovascular syndromes and many more [1].

With that in mind, it is hardly surprising that urology plays a special role within gender medicine: among the urinary organs, urology states the male genital apparatus as explicit organ of its discipline. Non-professionals often call urology even the 'medicine for men', in contrast to gynaecology being the 'medicine for women'. To understand these attributions and to extend interdisciplinary coworking (in areas such as female urinary incontinence), it is important to integrate gender research as an inseparable component of the urologic field [7].

The current World Journal of Urology's special issue acknowledges both the correlation of gender with urology and the significance of gender medicine. The 10 articles presented are providing a wide overview of the gender (and sex)-related topics within the area of urology.

Stenzl and Gakis [8] describe the role of sex-steroiddependent growth of muscle-invasive bladder cancer 
(MIBC) and the role of single-nucleotide polymorphisms (SNP) located on chromosome $8 \mathrm{q} 24$ as a molecular explanation for gender-specific differences in the incidence and outcome of MIB. Fajkovic and Shariat [9] analyse that female gender is associated with higher risk of disease recurrence in patients with primary $\mathrm{T} 1 \mathrm{high}$-grade urothelial carcinoma of the bladder. Klatte [10] shows in his study several gender-specific differences in benign renal tumours, especially in the histological types. Seitz and Fajkovic [11] identify gender-specific aspects in the prevalence, treatment and aftercare in urolithiasis patients with special attention to gender aspects associated with a history of kidney stones. Bauer and Hübner [12] provide a deeper insight into gender differences of bladder control and dysfunction. In the article on bladder outlet obstruction in men, Klatte et al. [13] identify clinical predictors with first episode of spontaneous acute urinary retention in order to facilitate patient selection for early deobstructive prostate surgery. Burger et al. [14] recognised the research gap of gender in urology and therefore analysed existing descriptions of gender effects in general oncological and uro-oncological research. Keck et al. [15] evaluate sex as a possible prognostic factor in bladder cancer patients treated by transurethral resection and radio- or radiochemotherapy. Brookman-May et al. [16] demonstrate the importance of gender differences in clinical and pathological features as well as the outcomes of patients with renal cell carcinoma after surgery. Roupret et al.'s [17] article critically reviews gender-specific differences in the incidence, prognosis and symptoms of the different subtypes of adrenal tumours.

We hope that this issue is an important starting point to understand the need of a gender-sensitive urology that not only addresses the differences in the sexes but also recognises sociocultural aspects and their impacts on the biology and the medical treatment of our patients.

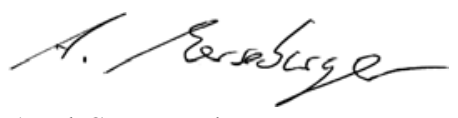

Axel S. Merseburger

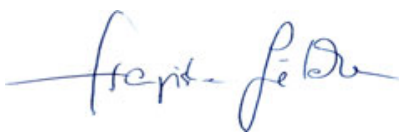

Franziska Gätcke

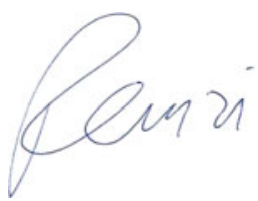

Mesut Remzi

August 2013

\section{References}

1. Oertelt-Prigione S, Regitz-Zagrosek V (2012) Sex and gender aspects in clinical medicine. Springer, London

2. Manson JE et al (1990) Aspirin in the primary prevention of angina pectoris in a randomized trial of United States physicians. Am J Med 89(6):772-776

3. Ridker PM et al (2005) A randomized trial of low-dose aspirin in the primary prevention of cardiovascular disease in women. N Engl J Med 352(13):1293-1304

4. Mosca L et al (2011) Effectiveness-based guidelines for the prevention of cardiovascular disease in women-2011 update: a guideline from the American heart association. Circulation 123(11):1243-1262

5. Kautzky-Willer AH (2012) Gendermedizin: prävention, diagnose, therapie. Böhlau UTB, Wien, Köln, Weimar

6. Regitz-Zagrosek VE (2012) Sex and gender differences in pharmacology, vol 214. Springer, London

7. Niederstadt CJ (2008) Weibliche Harninkontinenz-Urologie, Gynäkologie und Gender, in Gender Medizin. Geschlechtsspezifische Aspekte für die klinische Praxis. Rieder ALB (ed) 2004. Springer: Wien. pp 451-465

8. Gakis $G$ et al (2013) Gender-specific differences in muscleinvasive bladder cancer: the theory of sex steroid sensitivity. World J Urol. doi:10.1007/s00345-013-1037-z

9. Shariat SF (2012) Female gender is associated with higher risk of disease recurrence in patients with primary $\mathrm{T} 1$ high grade urothelial carcinoma of the bladder. World J Urol. doi:10.1007/ s00345-012-0996-9

10. Klatte $\mathrm{T}$ et al (2013) Gender differences in benign renal masses. World J Urol. doi:10.1007/s00345-013-1032-4

11. Seitz C et al (2013) Epidemiological gender-specific aspects in urolithiasis. World J Urol. doi:10.1007/s00345-013-1140-1

12. Bauer RM et al (2013) Gender differences in bladder control: from babies to elderly. World J Urol. doi:10.1007/s00345-0131132-1

13. Klatte $\mathrm{T}$ et al (2013) Bladder outlet obstruction in men with acute urinary retention: an urodynamic study. World J Urol. doi:10. 1007/s00345-013-1032-4

14. Burger $M$ et al (2013) Is gender becoming relevant in urological research? A bibliographic analysis. World J Urol. doi:10.1007/ s00345-013-1069-4

15. Keck B et al (2012) Female sex is an independent risk factor for reduced overall survival in bladder cancer patients treated by transurethral resection and radio- or radiochemotherapy. World $\mathbf{J}$ Urol. doi:10.1007/s00345-012-0971-5

16. Brookmann-May S et al (2013) Gender differences in clinicopathological features and survival in surgically treated patients with renal cell carcinoma-an analysis of the multicenter CORONA database. World J Urol. doi:10.1007/s00345-013-1071-x

17. Roupret $M$ et al (2013) Adrenal tumours are more predominant in females regardless of their histological subtype: a review. World J Urol. doi:10.1007/s00345-012-1011-1 